\section{BDJ STUDY ON DANGERS OF TEETH WHITENING PRODUCTS PROVOKES SIGNIFICANT MEDIA INTEREST}

A study ${ }^{1}$ published in the $B D J$ about the dangers of using over the counter (OTC) teeth whitening products has prompted a significant response in the media and dental world.

The study found that sodium chlorite, the active ingredient found in three over-thecounter products, could, in the presence of acid, 'significantly reduce the hardness of the teeth and increase the likeliness for future surface abrasions of the teeth.'

In Altmetrics - the system that measures the online attention an article receives and citations - the story had received a very high score by 6 March 2019, made up of coverage in 116 news outlets including the ITV news, Sky News, BBC World Service, Radio 5 live Drive, and the Daily Mail and Independent newspapers.

The study set out to determine whether non-hydrogen peroxide OTC whitening products available in the UK were safe and to determine the lightening effect of those products.

The researchers, led by the University of Manchester Dental School, tested five non-hydrogen peroxide whitening products from Boots and Superdrug on extracted

I teeth and found that three of the products

I had the active ingredient sodium chlorite

I that could reduce the hardness of teeth

I when acid was present while also raising

I the likelihood of future surface abrasions.

D I The BDA advised caution in using

(2) these products saying they could be either

\section{References}

ineffective or damage teeth. In addition, use of products that contained other chemicals that claimed to whiten teeth often failed to declare the exact chemicals used.

The trade union said it was aware that trading standards had seized DIY tooth whitening kits containing dangerous levels of hydrogen peroxide - more than $33 \%$ - highlighting the dangers that high level bleaching gels could cause, such as mouth infections, blistering and burns to gums, damage to nerves and tooth enamel, and gum-shrinking.

BDA Scientific Adviser Professor Damien Walmsley said: 'At best, people may be wasting their money buying over the counter and online products to whiten teeth. Home whitening kits are likely to take longer and be less effective than treatment from the dentist.

'While hydrogen peroxide, as used in dental practices, is the gold standard for whitening teeth, the lack of clarity over chemicals used in over the counter and online products means you could be gambling with your teeth.

'Some online products have been found to contain dangerous chemicals, including toxic or banned substances that can severely burn gums, or irreparably damage teeth.

'Dentists are trained to consider a patient's wider health and detect problems, such as gum disease, that impact on the suitability of an individual to have their teeth whitened. They also know what whitening products are effective to use and safe for teeth and gums.'

1. Greenwall-Cohen J, Francois P, Silikas N, Greenwall L, Le Goff S \& Attal J P. The safety and efficacy of 'over the counter' bleaching products in the UK. Br Dent J 2019; 226: 271-276. https:// www.nature.com/articles/s41415-0190011-6. (accessed February 2019)
Hey Duggee, Hey toothbroushing, Hey a-wodi?

The CBeebies cartoon character Hey Duggee has become an oral health influencer thanks to the British Society of Paediatric Dentistry! The third series of the show started last month and featured an episode devoted to teeth. Claire Stevens, spokesperson for BSPD, was acknowledged as a consultant to the programme.

Claire has two young children who are avid fans of Hey Duggee, the programme for children aged two to five. In 2017 she decided to write to the head of production at Studio Aka to see if tooth-brushing could become an activity at Hey Duggee's squirrel club. As it happened, the topic had already been mooted and Claire was invited to submit some content suggestions.

She took top tips from BSPD's A Practical Guide to Children's Teeth, including: brush twice a day with a fluoride toothpaste, spit don't rinse and Dental Check by One!

'The result,' says Claire, 'has been beyond my expectations. News of Hey Duggee's endorsement of toothbrushing spread like wildfire on social media. Now I hope we are going to see many more children engaged with brushing their teeth!'

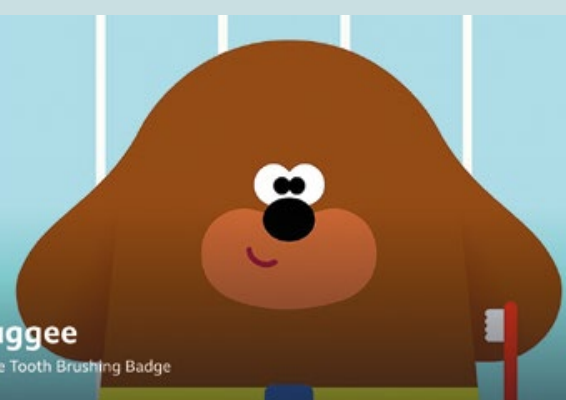

